\title{
The Impact of Family Conflicts on Children's Education.
}

\author{
Ndayambaje, E. ${ }^{1}$, Umwari, Y. ${ }^{2}$, Ayriza, Y. ${ }^{3}$ \\ ${ }^{1,3}$ Department of Psychology, Yogyakarta State University, Indonesia \\ ${ }^{2}$ Department of English Language Education, Yogyakarta State University, Indonesia \\ Corresponding email: edmond.ndayambaje@gmail.com
}

\begin{abstract}
This study aims to first identify the factors leading to family conflicts, and second to determine the impacts of such conflicts on children's education in order to improve family well-being. It involves a qualitative approach with a case study design. The targeted group consisted of ten participants: five females and five males. The purposive sampling technique was adapted to select the subjects. Concerning the size of the sample, it was preferred to use convenience sampling, due to the situation in the field where it was very difficult to firmly fix the respondents. An open-ended questionnaire with eight components was used to develop the questions connected to the scope of the study and the collected data were analysed through thematic analysis. The findings indicate that the prevailing factors in family conflicts in the region were miscommunication, mismanagement of family property, irresponsibility, and infidelity. Moreover, the majority of the respondents' children were quickly heading to very low academic performance compared to their school achievements prior to issues arising.
\end{abstract}

Keywords: children's education, convenience sampling, family conflict, thematic analysis.

\section{INTRODUCTION}

Conflict can arise within families either between partners themselves or between parents and children. Family life tends to be very complex and difficult to understand because every family has its own way of living and management. Many families are exposed to problems due to misunderstandings between family members. The family is an institution that has always faced numerous challenges and many parents end up getting divorced, which affects the well-being of their children. For instance, Borst (2015) found that family conflicts can increase the likelihood of the children being affected negatively. These negative effects might lead to others, such as impacts on their attachment style, their future relationships, and also their academic progress at school or college. Children from conflicted families are also at high risk of being negatively affected psychologically and socially. It is difficult for them to develop relationships with their friends or family members, and they have problems with settling down and with sleep disturbances, all of which mean they are likely to have lower performance at school (Reynolds et al., 2014). 
Family life should be characterised by good communication between its members, and close cooperation and collaboration so that everyone can live in harmony. Misunderstanding between family members, especially between spouses, can lead to family disequilibrium (Borst, 2015). Shantisree (2015) states that the family should be a place where the children grow and learn from the home environment. In addition, parental conflicts can impact the behaviour of their children, which may affect their personality. Dihn et al. (2017) found that family conflicts, especially between the father and mother, affect the mental health of the children, and that this will negatively affect their adult health. Such a phenomenon may result in barriers to development in the family and the community in general. Taking account of this crucial problem, Keith (2017) recommends that everyone participate effectively in preventing and fighting against family conflicts in order to maintain and improve family well-being. This is the focus of this study.

In Rwanda, through the different media we often hear about killings between spouses from the different family members, and the number of couples filing for divorce has been increasing over the years. For instance, according to Mbabazi (2018), the chief of justice reported that "there was 21 cases in 2016, 69 cases in 2017, and 1,311 cases in 2018". The separation of spouses and the destruction of conjugal life are often seen nowadays Rwandan society. The situation can deter young people from making the decision to get married, due to the fear of the prevailing situation in many families. According to Mukashema and Sapsford (2013), the issue of family conflicts in Rwanda has been increasing over days, and the main consequence is divorce or separation, which affects the parents themselves, but also especially the psychological health of their children. Such situations motivated the researcher to conduct this study on the causes of family conflicts and their relationship with children's education.

Human society built its systematic organisation on the nuclear structure, in which the fundamental elements is posed to the familial structure. In the family, both the wife and husband, as its main pillars, are responsible for providing education and other basic needs to their children and for making the family home a place of pleasure. As stated by Tolorunleke (2013), family members should be characterised by complementarity and should live in harmony; if not, the family could be destroyed and affected by such conflicts, and the children will be the victims. In a study of such effects, Shantisree (2015) found that children from conflicted families tend to be affected psychologically, especially in their way of thinking and their perception of the future. Family conflicts can also be the cause of poor academic performance, as discussed by Bahrassa et al. (2011). Nowadays, Rwandan society is experiencing several effects of family conflicts, which can destroy families as a result of divorces, the killing of spouses or suicide, with the children the victims of such situations, which will affect their well-being, especially their education.

Normally, the family tends to be always considered as the pillar of life, vital for present and future happiness. It is in the family that a child is conceived, born, educated and given to the community for the well-being of society (Shantisree, 2015; Mukashema \& Sapsford, 2013). The issues of safety and security are basic 
human rights, and yet many women, young people and very young children in Rwanda are unable to realise the full extent of their rights. Threats to their health and well-being, to their rights to education, and to their legal and economic rights as a result of gender-based and other forms of violence potentially limit their actual awareness of the rights guaranteed to them (MIGEPROF, 2011). Based on this, we were motivated to conduct a study with the objective of identifying the factors leading to family conflict in Rwanda, and to determine the relationship between such conflict and children's education. In addition, the study will also contribute to improving the welfare of Rwandan families and the education of the children. Therefore, the research will establish the main causes of family conflicts in Rwanda, analyse their relation to children's education, and propose possible measures and solutions to deal with such problems, particularly in the Rwandan context.

The family is a group of human beings who live together. In a strict sense, it is composed of a man and a woman who are married, and their children. All live together in the same house and help each other to achieve common projects. However, the daily life of the family is a complex situation affected by different daily stressors (Azcona, n.d.). The Rwandan family is always considered to be the core of life and the pillar of happiness in the future. It is within the family that a child is conceived, born, educated and given to the community for the well-being of the society. It is also within the family that the first interpersonal relationships are tied, exchanged, and compared. Moreover, identification opportunities are also obtained from the family. It is therefore essential to develop policies designed to strengthen and safeguard the family as an institution, and to enhance the quality of family relationships, taking into account the changes which occur in desired socioeconomic development (MIGEPROF, 2011).

The family is the first environment of the child; it therefore determines whether its affective evolution will be normal or pathological. Children who come from conflicted families are more likely to pass their thinking about their families, so they do not find the time to play with their friends. Family conflict has been found to pass from one generation to another. This intergenerational communication of family conflict is explained by family environmental factors such as conflict between parents and the role of childcare practices, which affect children's psychological development, whether parents and children are genetically correlated or not (Reynolds et al., 2014). Conflict is normally necessary and part of family life. However, when that between parents is solved in destructive rather than constructive ways, it can affect both parents and their offspring negatively. Children are strongly affected by conflict in their families, and parental conflicts influence children's development negatively. Children who experience parental conflict can develop symptoms of depression, and the greater the conflict, the more serious the symptoms (Schmidtgall, King, John, \& Cooper; 2000).

When children experience continuous conflicts between their parents they may also be affected, and they may imitate them in later life because of the dysfunctional relationships portrayed to them. By observing conflicts between parents every day, 
children may think that it is a normal situation and may follow such behaviour (Shantisree, 2015). The failure of marriages negatively affects the social well-being of the children caught up in the marital conflict that leads to parental divorce. Children develop problems in internalising and externalising their parents' relationship, leading to harmful effects, such as psychological, behavioural, emotional, cognitive, physical and social problems (Schmidtgall et al., 2000; Reynolds et al., 2014). Parental conflict can also affect children's academic performance, impact on the parent-child relationship and subsequently influence the way children build their relationships in the future (Mukashema \& Sapsford, 2013).

According to Njeru (2017), people get married with the hope of having a life-long satisfying union with their partner. They marry for love, for companionship, for friendship, for a family, for financial stability and for intimacy, among other reasons. The idea of staying married and having children while growing old together is the image most people who get married have. However, this is sometimes not the case, because marriage is no longer about family honour. People are getting married for the same reasons their parents did, but they are not the same people (Mukashema \& Sapsford, 2013). While before, marriage was arranged on the basis of social status and interfamily relations, now it is solely about personal happiness, which is why men and women are finding it easier to break up.

\section{MATERIAL AND METHODOLOGY}

The research is qualitative in its approach, exploring the views of family conflict predictors in Rwanda and their relation to children's education, in terms of (1) their extent; (2) their causes; (3) their consequences on children's education and (4) how to deal with them (possible solutions). The qualitative approach was taken for two main reasons: it is particularly useful for exploring points if little information exists, as is the case with family conflict in Rwanda, and it allows an overall interpretation which makes the major social significance of the data visible.

In this study, the researcher preferred to use convenience sampling, or accidental sampling, which is a type of nonprobability or non-random sampling, in which members of the target population meet certain practical criteria, such as easy accessibility, geographical proximity, availability at a given time, or willingness to participate, which are in line with the purposes of the study (Etikan, Musa, \& Alkassim, 2016). Our sample was restricted to 10 participants, composed of five men and five women, located in Kayonza District, Kabarondo sector. 30\% of participants were 35-40 years old, $20 \%$ were $40-45$ years old, $20 \%$ were $45-50$ years old, $20 \%$ were $30-35$ years old and $10 \%$ were $25-30$ years old. Ethical principles of confidentiality and anonymity were respected. The participants are identified by the initial letters of their names; K.A, N.C, N.A, N.B and UA were women, while G.N, T.E, K.A, M.T and N.F were men. A questionnaire was used to obtain information from participants, because this is the primary tool for data collection in survey research. Table 1 gives a summary of the themes on which the questions to the parents were based. During this research, data have been presented with themes as follow as: 
Table 1 Themes Emerging from the Data Analysis

\begin{tabular}{lll}
\hline Participants & \multicolumn{1}{c}{ Theme } & Questions \\
\hline & Theme 1: Family life and relationships & Qn1 \\
& Theme 2: Alcohol abuse & Qn2, Qn4 \\
& Theme 3: Lack of communication & Qn3, Qn5 \\
& Theme 4: Mismanagement of family property & Qn4 \\
Theme 5: Intimacy of family members & Qn5 \\
& Theme 6: Irresponsibility of partners & Qn6 \\
& Theme & Qn7, Qn8 \\
& Theme 7: Sexual infidelity & Qn8 \\
\hline
\end{tabular}

Source: Research conducted in Kabarondo sector.

\section{RESULTS AND DISCUSSION}

\section{Analysis of the results}

This section presents the data from the responses given by each participant interviewed, as well as the related analysis and interpretation. After gathering all the information from the participants, we proceeded to analyse it according to the themes established before the interviews.

\section{Theme 1: Family life and relationships}

On this theme, the question was designed to understand the negative effects of family misunderstandings on its daily functioning. During the research, all the participants stated that family conflicts between parents impacted on their children's education. They explained that

"The performance of our children at school became weak, even their school results are not satisfying" (reported by four parents).

"The level of concentration of their children decreased, and they cannot pay attention to what is said in class because they are easily distracted by thoughts about their family life" (reported by three parents).

"Our children became aggressive and they are not pleased by playing as used to be the case before" (reported by two parents).

"My children are worried about their health so they feel hopeless if they remember that their everyday life has been affected by conflicts between me and my husband" (G.C).

Children undergo many consequences based on the atmosphere in their families, as the family is where they spend much of the time. If the family is not safe, the children are burned and overwhelmed by the situation taking place. 


\section{Theme 2: Alcohol abuse}

On this theme, the question aimed to establish the link between alcohol consumption and family conflict. All the participants argued that alcohol abuse is one of the major causes of family conflicts.

Two participants reported that "excessive drinking is one source of conflict in our family because this causes our husband to squander the family property, which could be used for basic family needs, such as food, drink, clothing and shelter, which leads to irresponsibility in accomplishing what they could do for our family".

Three participants reported that their "partners became violent when they drank and they can't listen to what is said by other family members (wife and children), and they can't respond to their wishes, which is a source misunderstanding in the family".

Three women reported that "sometimes conflicts they had with their husbands were caused by drunkenness, when their husbands used money intended for the home; whenever they are drunk they make quarrels, otherwise there is peace when they don't drink beer."

It was also observed that all the male participants argued that alcohol drinking was not an issue, but that excess was a problem. Two men (K.E. and N.F) stated that "We don't know what happens when we arrive at home and we sometimes begin to insult and fight with our wives". Drunkenness causes quarrels in the family, which can also cause fights between family members in the case of any misunderstanding, and thus damage family relationships.

\section{Theme 3. Lack of communication}

On this theme, the question aimed to ascertain how miscommunication between family members could be the source of conflict. The study shows that a lack of communication between partners is the major source of family conflicts.

"If that occurs, every member begins to feel uncomfortable in the family and starts looking for another group to join. If found, they learn a new style of communication as long as they disregard the old one. That kind of difference bring troubles to our family" (reported by seven participants).

"I tried to keep because of our children, but my husband is impossible, he does not care for our children, it seems that he does not know that our quarrels affect them" (U.A).

"Most of the time our husbands don't allow us to give our views concerning the development of our family, they always say that the decision taken is unchangeable" (N.A and K.A). 
Nowadays, life is becoming complicated and expensive, and spouses are worried about the future of their families. If one is busy working and comes back home very late (specifically in the case of men), this can be one of the obstacles which limits the time for conversation between them. Later, this can affect their relationship and may cause conflicts within the family.

\section{Theme 4: Mismanagement of family property}

This question regards the mismanagement of family property by one partner without the consensus of the other; sometimes this can be the source of misunderstanding, as revealed in the study.

"I strongly disagree with my husband about the use our family property; he sells fields without telling me, or distributes them because he is drunk, and when I ask him about it, he responds that there is nothing I brought from my parents, and this causes me to think how he considers me and my purpose in the family as his wife is" (N.C).

"I don't want to identify my properties to my wife, I don't want her knowing my property; the essential thing for her is to get everything necessary she needs at home. There is no reason to show her all my property, because it is my own; I usually struggle for it myself, every morning I have to wake up and go to search for money, while she stays home. For that reason I don't see the purpose of showing her my property" (M.T).

"My wife took some crops like beans and sold them without informing me. I therefore have known that she sells them even at a lower price. I see that she wanted to be insubordinate to me, so I have taken the decision that the insubordination has to be resolved by insubordination, which means she can't ask me for money any more" (K.A).

"If I give money to my wife to buy things that are needed at home, she sometimes buys just a few of them, and with another part of the money, she uses it to enjoy herself with other women in bars, or elsewhere. Or I have given her other money to feed herself or to buy clothes, go to the hairdresser, etc., but she isn't satisfied with what I do for her. This is the source of our conflicts" (K.E).

The study shows that insufficient communication between partners leads to mistrust. Confidence between them decreases, and both begin to work as he/she needs, which leads to misuse of family property, with both using it as they want. Moreover, trust and reality are reduced, with one being able to possess their own property that is unknown by their partner. This ignorance and misunderstanding between them affect the family relationship and its development.

\section{Theme 5: Intimancy between partners}


Regarding the question on the intimacy of partners, during the research it was realised that when there is no respect or hope between partners, their intimacy decreases, which is one of the sources of their conflicts.

"Sometimes my husband organizes a trip himself; when he has somewhere to go, he plans for it alone and informs me too late. Arriving home, when I ask him when he had planned the journey, he sometimes responds to me that it was planned a long time ago, or it was something planned on the spur of the moment. If I ask him why he doesn't want to inform me, he responds that only I have to know that he has to go. I decided myself not to ask him such questions anymore; if he finds it necessary to do such a thing, maybe he will inform me" (N.C).

"My wife asks me for things that I am not able to get. If I don't give them to her, she sometimes cries, saying that she regrets accepting to be married to someone who is poor like me, who is not able to supply all her needs"'(G.N).

The study reveals that the origin of decreased intimacy is love based on materialism (specifically for the women). Sometimes they can love, but are motivated by their partner's possessions, arriving there if they missed what they suggested to have, this raises the misunderstanding between them, which can lower their intimacy.

\section{Theme 6: Irresponsibility of partners}

On this theme, the question was intended to understand how partners' irresponsibility can lead to family conflicts. As it has been seen, this is one of the major sources of misunderstanding in the family.

"The cause of conflicts with my wife is that she doesn't care for me, even for the children. She stays at home while I am at work, she doesn't even want to run a small business that can support the economy of our family, she doesn't want to do anything. And my question is how I will meet the whole family needs myself, while my wife is staying home, with nothing to do, and above that she doesn't want to recognise all the efforts I make for the welfare of our family, so that she can care $m e ”(\mathrm{~N} . \mathrm{F})$.

"My husband is irresponsible in taking care of our family; we have children who are studying, but it seems like they are not ours, because he does not give money to feed their needs like schools materials, uniforms, schools fees, etc. I arrange myself to cover their needs; I find him meaningless in our family" (N.C).

"Our children do not feel comfortable talking to their fathers, they keep a distance from them, a fact that increases the poor relationship in our families" (N.C and N.A).

"Sometimes my wife come home late; if I ask her where she is coming from, she replies that it is her right to come home any time, as I do too, because both of us 
are equals in front of the rules. Such responses sometimes make me sad, and we might fight immediately" (N.F).

"My wife is employed, but I'm still searching for a job, but even if I am employed, sometimes I have to move home and I meet with friends. Back home, my wife starts to insult me, saying I'm useless because I don't contribute anything at home, that I'm not responsible for my family, as I can't take care of it, only her"' (T.E).

Out of the problems of gender role claimed by men, three female participant also argued that:

"sometimes wives are confused about gender balance and complementarity; if they want to be equal with their husbands or it is not possible, due to our mentality and culture, Rwandan culture attributes some responsibilities to men and others to women".

During the research, we have also seen that the irresponsibility of some men is due to the issue of gender balance and human rights, with both men and some women arguing that this issue has been misinterpreted, which is one source of their misunderstanding.

\section{Theme 7: Sexual infidelity}

On this theme, the question aimed to know how infidelity or extramarital affairs were among the powerful reasons for conflict between couples. The research revealed it to be of the main issues in the family.

"I lived well with my husband when we were poor, we did our best and we worked a lot to eradicate that poverty. Fortunately we got money. Then my husband became arrogant; he sometimes went to look for the girls and women who are shining. Now I have become like a housewife, and he continues with other women and keeps using resources we have; they his become his wife for leisure" (N.C).

"My woman almost wants to be high, or I'm not able to satisfy all she needs, she is not satisfied with what I provide to her, so she leaves me to join those who can financially satisfy her" (G.N).

Sexual passion and attraction (especially for men) has also been identified as one of the main issues that causes spouse's sexual infidelity. Seven participants reported that: "ICT (computers, telephones, the internet and social media) constitutes the main way to facilitate communication, and the way to meet co-partners".

"The sexual dissatisfaction between spouses is caused by the way sexual relationships between them are conducted; sometimes is not sufficient when one finishes early, either due to tiredness, or cheating with others, which can make the other partner become unfaithful in order to be satisfied too" (reported by all participants). 
The study has shown that some husbands have extramarital affairs because they want to have sex more frequently than their wives, so when the wife refuses to have sex when the husband wants to, the husband goes out to find other girls to satisfy his sexual desire, which can be the cause of misunderstandings between them. This also results in the habit of cheating, especially when one partner was accustomed to do so before their wedding, so most probably the behaviour returns after the marriage.

\section{Theme 8: Intercourse relationship between partners}

On this theme, the question aimed to establish how the dissatisfaction of one partner can be the source of misunderstanding between spouses. From the data collected all the participants argued that the way their partners made love was sometimes not sufficient. This can form part of the misunderstanding between them and also affect their relationship, as they reported.

"I sometimes want sex, but I get scared and ashamed to ask my husband for it. Then he sometimes wants to have sex when I no longer want it, and even if I accept do so, I do not feel good and comfortable, which affects our relationship" (N.C).

"My husband goes to bars and he comes back home like at 11.30 pm at night and forces me to have sex while I'm sleeping, and he wants me to have sex even without preparing me. Sometimes I refuse and we have quarrels, what raises the conflict between me and him" (N.A).

"Most times my wife does not want to have sex; if I ask her why, she responds that she is tired. Sometimes I persist, or no, if she refused totally. I think maybe she has other men who are used to doing that for her" (T.E,).

All participants (both men and women) argued that sex between partners was one of the bases of their good relationship, and that partners had sex for the following reasons: to satisfy their physiological needs, to have children (procreate) and then to be best friends and to strengthen their relationship.

\section{Discussion}

\section{Family conflict}

Family conflict in Rwanda today is something that seems to be observed everywhere, in towns, in the countryside, among young partners and even among older ones, but the most serious problem which is worthy of concern, is seen as to lie with younger couples. There are some who spend only two or three years in relative harmony, but after the first or second child is born problems and conflicts occur, as stated by Mukashema and Sapsford (2013). The clash between what people expect of marriage and what they experience in it is a major reason for family conflict. In this study we have found that people get married to fulfil their 
own needs, without considering that there is a great deal more to marriage than just what they are looking for. The main reason why marriages break down is highly compatible with the psychology of personal construction: the social world is perceived though our expectations of it; people bring their prior understandings of what marriage is to the actual marriage and expect their needs to be met on the basis of these expectations. In this study, it has been realized that unrealistic expectations of marriage are the main cause of family conflicts.

Everyone comes from a family, and therefore most of us can understand what a family is. Communication within the family is extremely important, because it enables members to express their needs, wants and concerns to each other. Open and honest communication creates an environment that allows all family members to express their views, as well as their love and admiration for one another. It is through communication that family members are able to resolve the unavoidable problems that arise in all families. Effective communication is usually found to be healthy for the family, while poor communication is usually found to be unhealthy for family relationships.

Marriage and family therapists often report that poor communication is a common complaint in families who are having difficulties, as stated by Borst (2015) and Dinh et al. (2017), and that poor communication is unclear and indirect. This can also lead to various family misunderstandings, including excessive family conflicts, less communication in problem solving, a lack of intimacy, and weak emotional attachment (Peterson, 2009). Not only do unresolved family conflicts weaken the relationship between partners, but it can also end up in divorce later, as has been revealed in this study. Most of the participants argued that if their spouses were not able to resolve their family conflicts, they would separate, and thus the family would be destroyed.

\section{Family conflict and children's education}

The research has revealed that there is a close relationship between family conflicts and children's education. Children face many consequences based on the atmosphere of their families, and the family is where they spend much of the time. Our findings are in line with those of Shantisree (2015), who found that if the family is not safe, the children are burned and overwhelmed by the situation. Shantisree also stated that the family should be regarded as the first school and the parents as the first teachers. As such, they should stimulate children's minds so that they are interested in learning. A home that makes the child feel secure enough to venture forth and explore his surroundings and parents who are responsive to the child and who interact with him, facilitate the child's cognitive growth. This is in line with the study by Dihn et al. (2017), who found that children who come from conflicted families are more likely to pass their thinking about their families, so they do not find the time to play with their friends.

This research also found that children from conflicted families are worried about their health, so they feel hopeless because their everyday life has been affected by the conflicts of their parents. Parental conflicts influence children's development 
negatively. Our findings also are in line with Njeru (2017), who found that children developed problems in internalising and externalising parental relationships, leading to harmful effects. When children are exposed to everyday conflicts between parents, they develop psychological, behavioural, emotional, cognitive, physical and social problems, as also found by Mukashema and Sapsford (2013) and Dihn et al. (2017).

Parental conflicts affect children's academic performance, and parent-child relationships influence how children perceive and build their relationships in the future. Children who have experienced parental conflicts and separation have less commitment and confidence in the future of their marriage (Dihn et al., 2017). When children experience non-stop conflicts between their parents, they may also imitate them, which can affect the way they build their later relationships modelled on them. By watching everyday conflicts between their parents, children may think that it is acceptable to behave in this way and may imitate such behaviour (Mukashema \& Sapsford, 2013).

Parental conflicts influence parent-child relationships, which affects children's attachment to their parents, leading to increased aggressive and depressive symptoms in them. Research also shows that aggression caused by parental conflicts affects peer relationships in children and behaviour problems in adolescents. In terms of physical development, parental conflicts are also related to anxiety and insecurity in children, which further lead to sleep and other health problems (Schmidtgall et al., 2000).

\section{Possible solutions proposed by the participants}

During the research, all the participants who were interviewed gave some suggestions on preventing family conflicts. They gave their requests to their spouses, to the community and finally to administrative authorities and nongovernment organisations (NGOs).

People should be careful and attentive when making a choice for their future partner. In any misunderstanding, they should take time and discuss the problem, seeking a solution themselves. Partners should also have a consensus about the use of family property. Finally, family members must be characterised by flexibility and forgiveness in the case of any problem or misunderstanding.

The community in general should be empathetic and advise families in conflict, instead of being unconcerned or not wanting to be implicated. In addition, society should go back to Rwandan traditional values such as honesty and respect, to avoid any habit that can affect other families, such as alcohol abuse, irresponsibility, cheating, etc.

The administrative authorities and NGOs should do all their best to prevent conflicts before they happen, especially local authorities, who should help families by advising on and solving their misunderstandings. They should also organise 
different campaigns aimed at explaining more about gender roles and human rights, for the welfare of families and society. Finally, they should advise families having legal marriage, and educate partners (before marriage) about the responsibility of everyone in the family. Finally, professionals in the domain of family conflicts should be trained in this issue so that they can intervene when necessary.

\section{CONCLUSION}

The research was qualitative in approach, and explored the views of men and women who willingly participated about family conflicts in Rwanda, in relation to (1) their extent, (2) their causes, (3) their impacts on children education, and (4) possible measures and solutions to how to deal with them, particularly in the Rwandan context. Family conflicts are typically more intense than conflicts in other groups. This intensity means that managing them may be more difficult in families, and their consequences may be more damaging. The study has revealed that miscommunication, alcohol abuse, misuse of family property, irresponsibility and sexual infidelity are the main causes of family conflicts in Rwanda. In addition, poverty, HIV/AIDS and demographic explosion are also current problems facing Rwandan families.

The research also found that family conflicts have consequences on children, in terms of mental illness or psychological disturbance, which affects their education and the way they perceive their future. As for measures that could be taken, the findings suggest that the administrative authorities and NGOs should work together to sensitise everyone about gender roles and human rights. This strategy could be added to regular meetings, after the monthly activity commonly known as "UMUGANDA". Religion could also be involved by helping in family conflict resolution, especially at a preventive level. From the findings, professionals in the domain of family conflict resolution should be trained and be available for the prevention and management of family conflicts.

\section{ACKNOWLEDGMENTS}

In the study, the authors used primary data collected in Kayonza district, Kabarondo sector. We are thankful to the Rwandan people who participated and the local authorities who helped us during the data collection.

\section{REFERENCES}

Azcona, M. C. (n.d.). Resolution of Family Conflicts Through Literature. Retrieved on March 28, 2018, from https://www.eolss.net/sample-chapters/C04/E1-39A-28.pdf

Bahrassa, N. F., Syed, M., Su, J., \& Lee, R. M. (2011). Family Conflict and Academic Performance of First-Year Asian American Undergraduates. Cultural Diversity and Ethnic Mitiority Psychology, 17(4), 415-426 
Borst, Jacob B.. (2015). A Systematic Review of the Effects of Family Conflict: Focusing on Divorce, Infidelity, and Attachment Style. Retrieved from Sophia, the St. Catherine University repository website: https://sophia.stkate.edu/msw_papers/426

Dinh, H., Cooklin, A. R., Leach, L. S., Westrupp, E. M., \& Nicholson, J. M. (2017). Parents' transitions into and out of work-family conflict and children's mental health : Longitudinal in fluence via family functioning, Journal of of Social Science \& Medicine, 194(June), 4250. https://doi.org/10.1016/j.socscimed.2017.10.017

Etikan, I., Musa, S. A., \& Alkassim, R. S. (2016). Comparison of Convenience Sampling and Purposive Sampling. American Journal of Theoretical and Applied Statistics, 5 (1)(February), 1-4. https://doi.org/10.11648/j.ajtas.20160501.11

Keith, B., \& Amato, R. P. (2017). Parental Divorce and the Well-Being of Children: A MetaAnalysis. Journal of Marriage and Family, 53(April 2017), 17. https://doi.org/10.1037/0033-2909.110.1.26

Mbabazi D. (2018, November 29). Till Divorce Do us Part: Why the Rise in Separation? The New Times_Rwanda's Reading Daily. Retrieved from https://www.newtimes.co.rw/lifestyle/till-divorce-do-us-part-why-rise-separation

Ministry of Gender and Family Promotion, MIGEPROF, (2011). National Strategic Plan for Family Promotion_Fighting Against Gender-based Violence 2011-2016 (Issue August).

Mukashema, I., \& Sapsford, R. (2013). Marital Conflicts in Rwanda : Points of view of Rwandan Psycho-Socio-Medical Professionals. Procedia - Social and Behavioral Sciences, 82, 149168. https://doi.org/10.1016/j.sbspro.2013.06.239

Njeru, M. W. (2017). The Effects of Parental Divorce on Adolescents: A Focus on the dimensions of the wellness model. Retrieved from http://erepo.usiu.ac.ke/bitstream/handle/11732/3342/Mercy Wawira Njeru Ma Clinical Psychology.pdf?sequence $=1 \&$ isAllowed $=\mathrm{y}$

Peterson, R. (2009). Families First: Keys to Successful Family Functioning Communication. Retrieved from https://pubs.ext.vt.edu/content/dam/pubs_ext_vt_edu/350/350-092/350092_pdf.pdf

Reynolds, J., Houlston, C., Coleman, L., \& Harold, G. (2014). Parental conflict: outcomes and interventions for children and families Executive Summary. http://knowledgebank.oneplusone.org.uk/wp-content/uploads/2014/04/ParentalConflict.pdf

Schmidtgall, K., King, A., John, J. Z., \& Cooper, E. J. (2000). Journal of Divorce \& The Effects of Parental Conflict on Later Child Development. Journal of Divorce \& Remarriage, 33: 12(October 2014), 149-157. https://doi.org/10.1300/J087v33n01

Shantisree, T. (2018). Marital Discord of Parents and its Influence on Adolescents' Self Esteem, Anxiety and Coping Strategies: An Intervention Study. Scholarly Research Journal for Interdisciplinary Studies, 6/47(2), 227-249.

Tolorunleke, C. A. (2014). Causes of Marital Conflicts amongst Couples in Nigeria : Implication for Counselling Psychologists. Procedia - Social and Behavioral Sciences, 140, 21-26. https://doi.org/10.1016/j.sbspro.2014.04.381 